\title{
A FORMAÇÃO COM AS IMAGENS
}

Nilda Alves ${ }^{\mathrm{i}}$

Universidade do Estado do Rio de Janeiro

nildag.alves@,gmail.com

\section{Resumo}

Neste artigo, parto da ideia de que a formação docente se dá em redes educativas múltiplas e complexas e que se articulam entre si de modos diferenciados em espaçostempos diferenciados. Articulando esta idéia ao pensamento de Certeau acerca da questão das crenças quando entende que hoje elas estão basicamente no setor político e são relacionadas às redes midiáticas, a partir de uma compreensão do real que se forma a partir de construções de dados e fatos pela mídia, em especial. Com esta base, analisamos os recentes acontecimentos políticos no Brasil, buscando entender a formação referida, dentro da sua complexidade.

Palavras-chave: Cotidiano. Redes educativas. Crenças políticas. Real.

\begin{abstract}
In this article, I start from the ideia that the teacher's formation occurs in multiples and complexes educational networks that are mutually interconnected in different ways in different spacestimes. Articulating this idea to Certeau's thoughts about the issue of beliefs when it is understood that today they are basically in the political sector and are connected to the mediatics networks, from a comprehension of real formed from constructions of data and facts by the media, especially. With this base, we analyzed the recent political happenings in Brazil, searching to understand the mentioned formation, inside its own complexity.
\end{abstract}

Keywords: Everyday. Education networks. Political beliefs. Real

\section{A FORMAÇÃO COM AS IMAGENS}

Há anos trabalhando com a ideia de redes educativas que entendemos ${ }^{\mathrm{ii}}$ serem formadas pelos seres humanos em suas múltiplas e complexas relações e nas quais eles se formam com os outros, chegamos à compreensão de que poderíamos identificar algumas delas que entendemos serem as que atuam de modo mais intenso na formação de todos nós, em sociedade. Desse modo, assim, as nomeamos: a das práticasteorias da formação acadêmica; a das práticasteorias pedagógicas cotidianas; a das práticasteorias das políticas de governo; a das práticasteorias coletivas dos movimentos sociais; a das práticasteorias das pesquisas em educação; a das práticasteorias de produção e 'usos' de mídias; a das práticasteorias de vivências nas cidades (no 
campo ou à beira das estradas) (ALVES, 2010). Mais recentemente, entendemos que em todas essas redes são formados "mundos culturais" diversos, conectados em múltiplos espaçostempos e nos quais as artes têm especial papel articulador e de referência aglutinadora (ALVES; CALDAS; ROSA, 2016; 2015). Atuando, diferentemente, mas relacionadas umas com as outras, com intensidades diversas segundo os espaçostempos de realização, essas redes estão presentes nos modos como devemos compreender e como trabalhamos a formação dos praticantespensantes (OLIVEIRA, 2012) docentes, mesmo que não tenhamos isto claramente identificado, ainda.

Trabalhando há anos com imagens e sons, em diversos artefatos culturais ${ }^{\mathrm{iii}}$, pudemos perceber a intensidade com que umas e outros se articulam nas vidas de todos nós e os modos como atuam na formação dos seres humanos.

Já com algumas páginas escritas para dar conta de como a última dessas pesquisas nos ajudou a melhor compreender esta formação, os acontecimentos políticos em nosso país me obrigaram a pensar melhor no que escrever neste artigo acerca das questões que tanto nos mobilizaram nos últimos meses e como se dá a formação política na contemporaneidade, com reflexos importantes sobre a crise que vivemos.

Decido então enfrentar esta questão e que, recente usuária do Facebook, é preciso tratar, talvez, de imagens que circularam neste artefato e me levaram a entender algumas outras coisas acerca desta formação.

\section{Um contexto ou os contextos? Ou seria "acerca do real"?}

No primeiro livro da "Invenção do cotidiano",iv , depois de apresentar formas de entender a prática - de Kant a Durkheim; de Foucault a Bourdieu - Certeau (2012) ${ }^{\mathrm{v}}$ busca mostrar o que de diferente deve ser estabelecido nos estudos com os cotidianos, para que se possa pensar as práticas - e as teorias criadas em torno da compreensão delas - de outro modo. Para isto, ele propõe se aproximar de inúmeros espaçostempos nos quais é possível compreender os processos do fazer ${ }^{\mathrm{vi}}$ cotidiano. Um desses, ainda muito pouco 'usado' vii pelos que pesquisam com os cotidianos se intitula Maneiras de crer. É com este que busco analisar o momento presente do Brasil e no mundo - "modestamente", como costumo brincar com os orientandos do grupo que coordeno quando eles apresentam uma questão extremamente complexa para pesquisas nos trinta meses de Mestrado e quarenta e oito meses de Doutorado. Sento-me um pouco como eles, hoje, buscando entender uma questão tão ampla. Vou, assim, trazer de Certeau o que me ajudará analisar os modos de ser nos cotidianos que atuam na formação política de todos nós nas tantas 
redes educativas em que esta se dá, comentando o momento presente da política brasileira, com as movimentações intensas e postas que aconteceram e acontecem atualmente.

Buscando caracterizar o momento atual acerca das crenças, entendendo que hoje elas estão basicamente no setor político e são relacionadas às redes midiáticas, Certeau (2012) começa um sub-item a que chama $A$ instituição do real com o seguinte parágrafo:

o grande silêncio das coisas muda-se no seu contrário através da mídia. Ontem constituído em segredo, hoje torna-se tagarela. Só se veem por todo o lado notícias, informações, estatísticas e sondagens. Jamais houve uma história que tivesse falado ou mostrado tanto. Jamais, com efeito, os ministros dos deuses os fizeram falar de uma maneira tão contínua, tão pormenorizada e tão injuntiva como o fazem hoje os produtores de revelações e regras em nome da atualidade. Os relatos do-que-estáacontecendo constituem a nossa ortodoxia. Os debates de números são as nossas guerras teológicas. Os combatentes não carregam mais as armas de ideias ofensivas ou defensivas. Avançam camuflados em fatos, em dados e acontecimentos. Apresentam-se como os mensageiros de um "real". Sua atitude assume a cor do terreno econômico e social. Quando avançam, o próprio terreno parece que também avança. Mas de fato eles o fabricam, simulam-no, usam-no como máscara, atribuem a si o crédito dele, criam assim a cena da sua lei. (...) O real contado dita interminavelmente aquilo que se deve crer e aquilo que se deve fazer. E o que se pode contrapor aos fatos? A pessoa tem que se inclinar e obedecer aquilo que 'significam', como ao oráculo de Delfos. A fabricação de simulacros fornece assim o meio de produzir crentes e, portanto, praticantes. Esta instituição do real é a forma mais visível de nossa dogmática contemporânea. É também a mais disputada entre partidos (CERTEAU, 2012, p. 259-260).

Ao reler este trecho, meu primeiro movimento foi me perguntar: por que antes eu não enxerguei isto? Por que, apesar da clareza do modo de tratar e dos argumentos de Certeau, eu não conseguira, até hoje, relacioná-los ao que estava vendo acontecer a minha volta? E por que passei a vê-lo e entendê-lo em sua maior expressão agora?

Os acontecimentos políticos atuais em nosso país, com a atuação central e quase decisiva das mídias hegemônicas, nos fez reler o texto acima, com outros olhos, sem dúvida. Ele se articulou às questões que me punha, no presente, ganhando relevância nas explicações de que precisava. É preciso lembrar sempre que nosso pensamento se renova com nossa história pessoal e geral, com o que enfrentamos cotidianamente nas redes educativas por que circulamos.

Buscando explicar como com a Modernidade a crença da Igreja - a única até então existente, a católica - vai passando para o setor civil, enquanto a religião se parte em mil 
diferentes pedaços acerca do modo de crer, Certeau (2012) traz de volta, brevemente, o pensamento de Rousseau, no que este denominou de religião civil. Sobre isto, escreve Certeau citando este filósofo:

ao Estado pagão que "não distinguia seus deuses e suas leis", Rousseau opõe uma "religião" do cidadão, "onde pertence ao soberano fixar os seus artigos". "Se alguém depois de ter publicamente reconhecido esses mesmos dogmas, se comporta como não acreditando neles, seja punido de morte". (...) Essa visão profética, muito menos incoerente do que se dizia, já articula o desenvolvimento de uma dogmática "civil" e política sobre a radicalização de uma consciência individual desligada de todo dogma e privada de poderes. (CERTEAU, 2012, p 256-257)

O que se viu em manifestações raivosas - coletivas e individuais - durante as manifestações que antecederam o estabelecimento do processo de impeachment da Presidenta, no Brasil, nos mostrou isto muito bem. Trago já aqui, algumas imagens que circularam no Facebook buscando pensar com elas e fazendo delas personagens conceituais ${ }^{\text {viii }}$ (DELEUZE e GUATTARI, 1992):

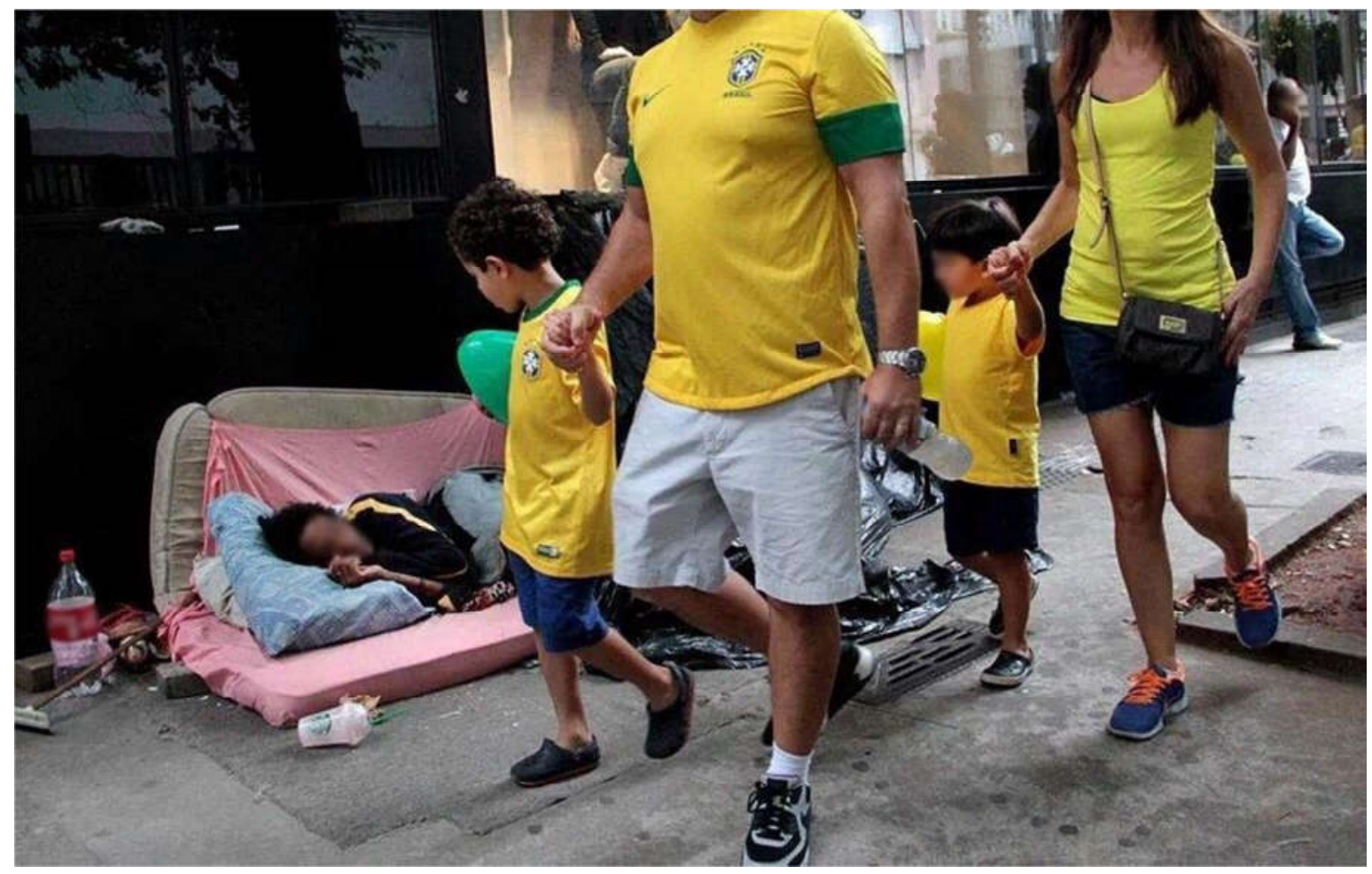

Imagem 1 


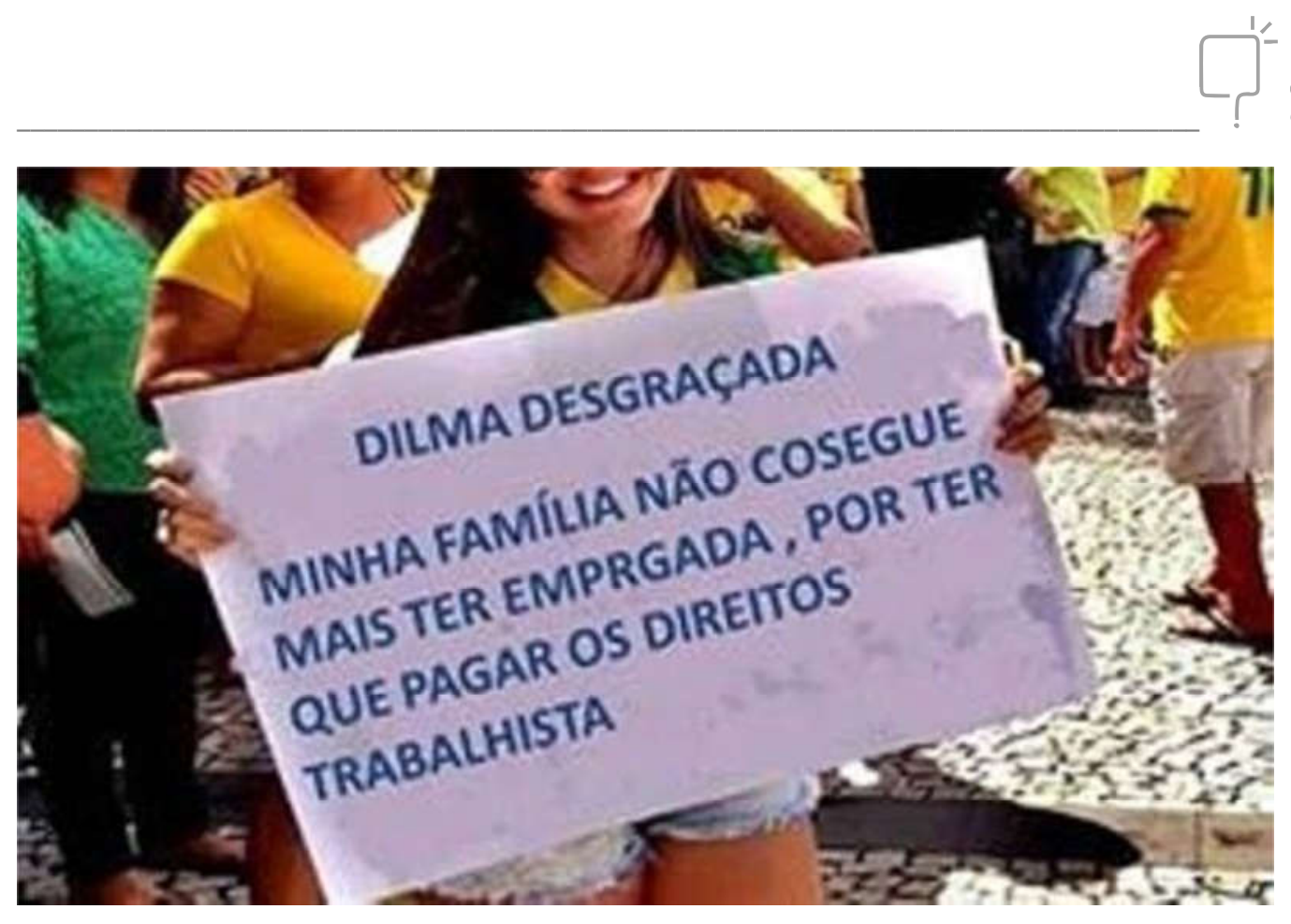

Imagem 2

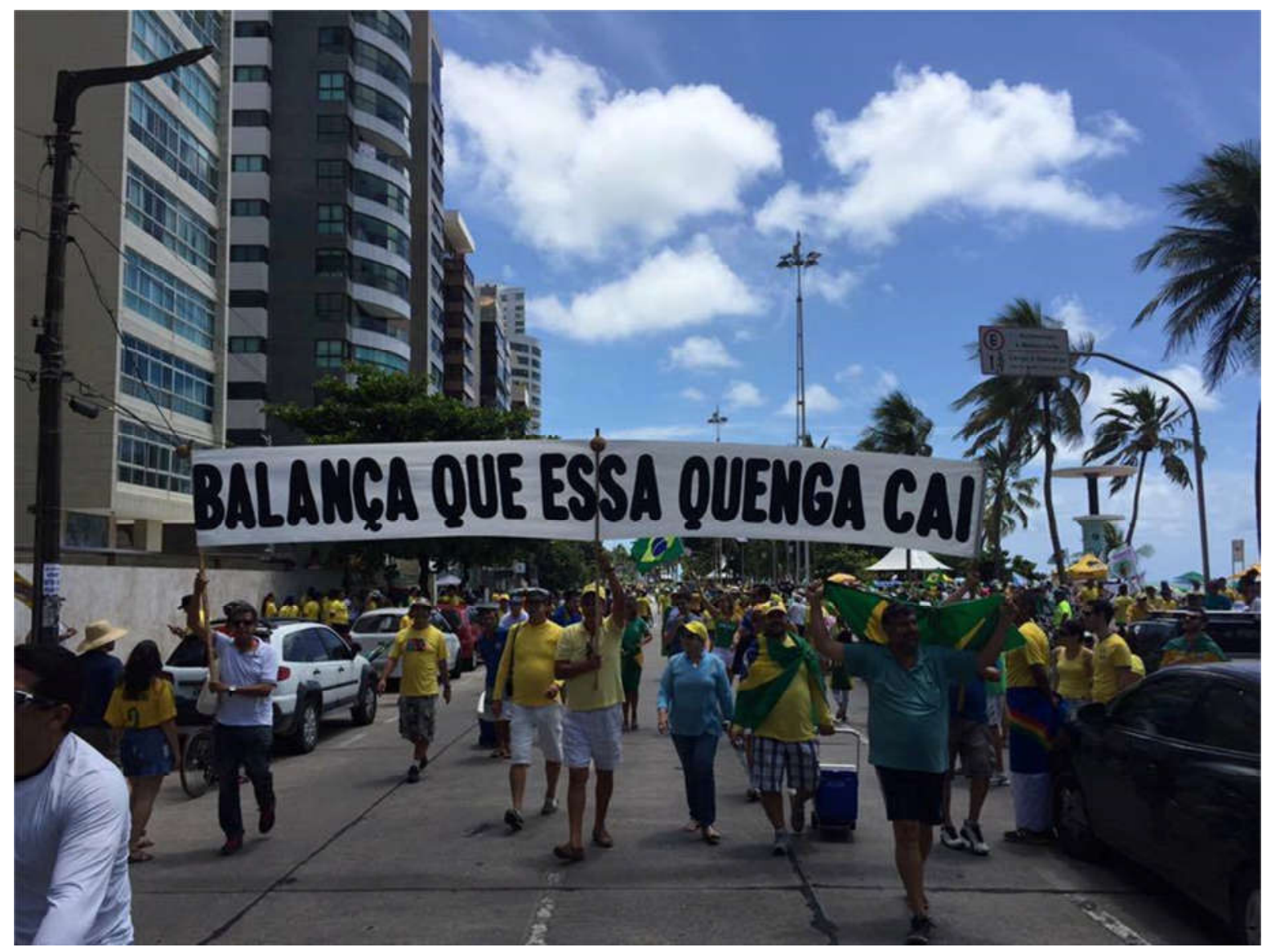

Imagem 3 


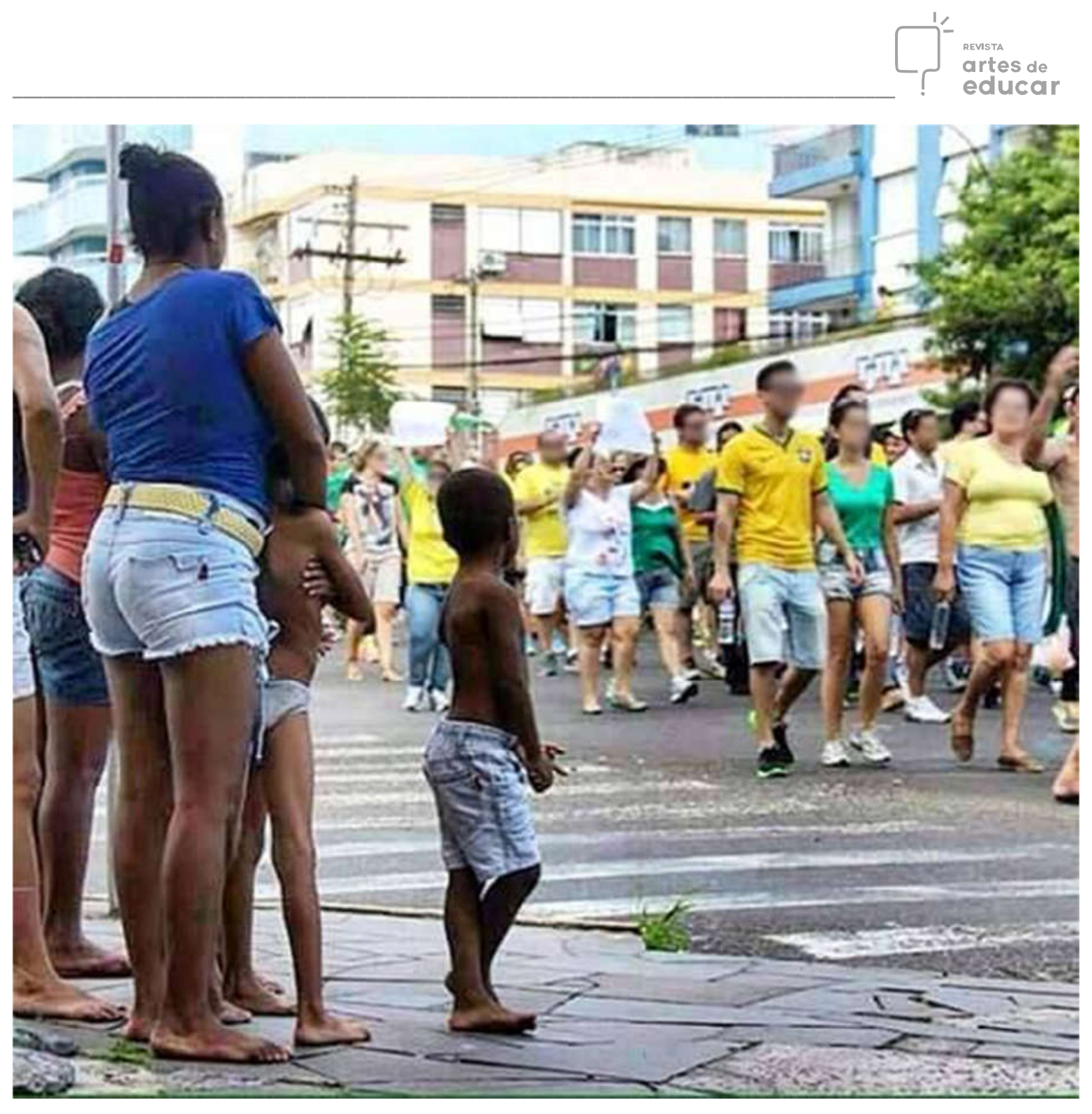

Imagem 4

De ofensas pessoais à Presidenta a reivindicações escravocatas, passando por indiferença aos que efetivamente precisam ${ }^{\text {ix }}$, a religião civil se pronunciou como quis, estando presente de maneira espetacular nas mídias hegemônicas, sempre. Todos 'sabiam' estar representando a muitos e portavam 'crenças' muito arraigadas - afinal ouviam isto todos os dias na televisão.

Essas imagens e esses 'portadores' da religião civil, no presente, no Brasil, são trazidas para este texto para que possamos entender que é dentro deste contexto e possibilidades de criação do real que a formação política se dá, neste momento no Brasil e no mundo.

É no movimento que faz acerca de como o real é articulado, na contemporaneidade, que Certeau contribui para que possamos discutir esta formação, hoje. 
Inicialmente, Certeau (2012) nos diz que os processos de crer nas formações políticas permitem distinguir "dois dispositivos pelos quais uma dogmática sempre se impôs à crença". São eles, segundo este autor:

de um lado, a pretensão de 'falar em nome de um real' que, supostamente inacessível, é ao mesmo tempo o princípio daquilo que é criado (uma totalização) e o princípio do ato de crer (uma coisa sempre subtraída, inverificável, ausente); de outro lado, a capacidade do discurso, autorizado por um 'real' para se distribuir em 'elementos organizadores de práticas', isto é, em 'artigos de fé'. Essas duas forças tradicionais se acham hoje no sistema que combina com a narratividade da mídia - uma instituição do real - o discurso dos produtos de consumo - uma distribuição do real em 'artigos' em que se deve crer e comprar (CERTEAU, 2012, p. 259).

Com isto, passamos então, aos modos como se institui o real, pela narratividade da mídia e com a distribuição de 'artigos' a se comprar: se não 'acredito' que devo pagar à empregada doméstica como aos outros trabalhadores, culpo a quem assinou a lei que as transformou nisso (Imagem 2). Se tenho um emprego que me permite cuidar bem da minha família, porque notar quem dorme e vive na rua (Imagem 1)? Com a visualização permanente de dados, na televisão, que mostram como a empresa de petróleo do país só faz acumular prejuízos pela enorme corrupção que nela campeou e que um juiz nos mostra com o desenvolvimento de um processo também midiático, acredito que posso escrever em uma faixa o que quiser sobre a Presidenta (Imagem 3). Por fim, acredito que sou maioria mesmo que uma parte importante da população brasileira - a que ensaiou e em alguns casos conseguiu sair da miséria - esteja à margem das manifestações que faço (Imagem 4).

Tudo isto porque as informações não comportam mais

um lugar social, nem cátedra ou magistério. Código anônimo, a informação inerva e satura o corpo social. Desde a manhã até a noite, sem pausa, histórias povoam as ruas e os prédios. Articulam nossas existências ensinando-nos o que elas devem ser. "Cobrem o acontecimento", ou seja, fazem deles as nossas legendas (legenda: aquilo que se deve ler e dizer). Apanhado, desde o momento em que acorda pelo rádio (a voz é a lei), o ouvinte anda o dia inteiro pela floresta das narratividades jornalísticas, publicitárias, televisionadas, que, de noite, ainda introduzem as suas últimas mensagens sob as portas do sono. Mais do que o Deus narrado antigamente pelos teólogos, essas histórias desempenham uma função de providência e de predestinação: elas organizam de antemão nossos trabalhos, nossas festas e até nossos sonhos. A vida social multiplica os gestos e os comportamentos 
impressos por modelos narrativos; reproduz e empilha sem cessar as "cópias" de relatos. A nossa sociedade se tornou uma sociedade recitada e, isto, num triplo sentido: é definida ao mesmo tempo por relatos (as fábulas de nossas publicidades e de nossas informações), por suas citações e por uma interminável recitação $o^{x}$.

Esses relatos têm o duplo e estranho poder de mudar o ver num crer e de fabricar real com aparências. Dupla inversão. De um lado a modernidade, outrora nascida de uma vontade observadora contra a credulidade e se fundava num contrato entre a vista e o real, transforma agora esta relação e deixa ver precisamente o que se deve crer. A ficção define o campo, o estatuto e os objetos da visão. Assim funcionam os mass media, a publicidade e a representação política (CERTEAU, 2012, p. 260-261).

\section{A circulação de imagens no Facebook - uma primeira aproximação para entender as crenças}

A aceleração dos meios de comunicação e a criação e uso da Internet permitiram, assim e também, a ocupação desta como meio que funciona do mesmo modo para divulgar crenças, no qual contam as informações 'materializadas' em números, em afirmativas sem necessidade de comprovação, em acordo com as redes a que pertence quem as vê/lê e dela participa, escrevendo, postando imagens de diferentes origens e conteúdos.

No entanto, a Internet tem funcionado também como outra mídia que embora repetindo fatos, dados, acontecimentos e imagens (fixas e em movimento), pois os 'posts' com intervenções diversas ou os blogs criados para dizer coisas em torno de determinadas ideias vêm permitindo circulações outras, diferentes daquelas que se dão/são produzidas a partir da chamada grande imprensa - escrita, falada ou televisada. Isto tem funcionado no mundo inteiro: lembremos a Primavera Árabe ${ }^{\mathrm{xi}}$; o Occupy Wall Street ${ }^{\mathrm{xii}}$, em Nova York; os movimentos de rua em 2013 ${ }^{\text {xiii }}$, no Brasil, entre tantos outros movimentos pelo mundo todo (CASTELLS, 2013).

Vale pararmos para ver como de dá e porque se dá - e como nos formam - a circulação de certas palavras de ordem ou ideias fixas, através de imagens na Internet, em uma primeira aproximação.

Posso exemplificar, no contexto atual com ideias ligadas ao processo de impeachment da Presidenta da República e com todos os processos políticos que se desenvolvem no Brasil, atualmente.

Dentro desses, tomou especial relevo, por exemplo, a que ficou conhecida como Fora Temer que vai aparecer de execuções musicais a cartazes em papel A4, folha de cartolina, camisetas ou pedaços de pano. Com a proibição - ninguém sabe de que origem - de que cartazes com essa referência estivessem presentes nos jogos das olimpíadas, já que havia a possibilidade 
de aparecer na televisão, em especial na rede hegemônica, a variedade de como burlar a vigilância na entrada e de como se posicionar para que o escrito aparecesse, fazendo fotografias que eram, imediatamente, enviadas para as páginas do Facebook, e cuja transmissão, neste meio, se multiplicaram. Uma das últimas dessas imagens foi aquela que apareceu, nas arquibancadas, em um pequeno pedaço de tecido (mais fácil de esconder nas roupas do que em folha de cartolina, como foi a maioria) atrás dos saltadores de vara, no dia da vitória do brasileiro Tiago Braz da Silva. A outra foi a sequência de faixas amarradas nas grades de contenção na passagem da Maratona masculina que fecha as provas.

Algumas imagens, no entanto, em torno desses acontecimentos - processo de impeachment; 'Fora Temer' - trouxeram inúmeras facetas do processo vivido neste meio. Trazemos algumas delas para pensar sobre formação com elas:

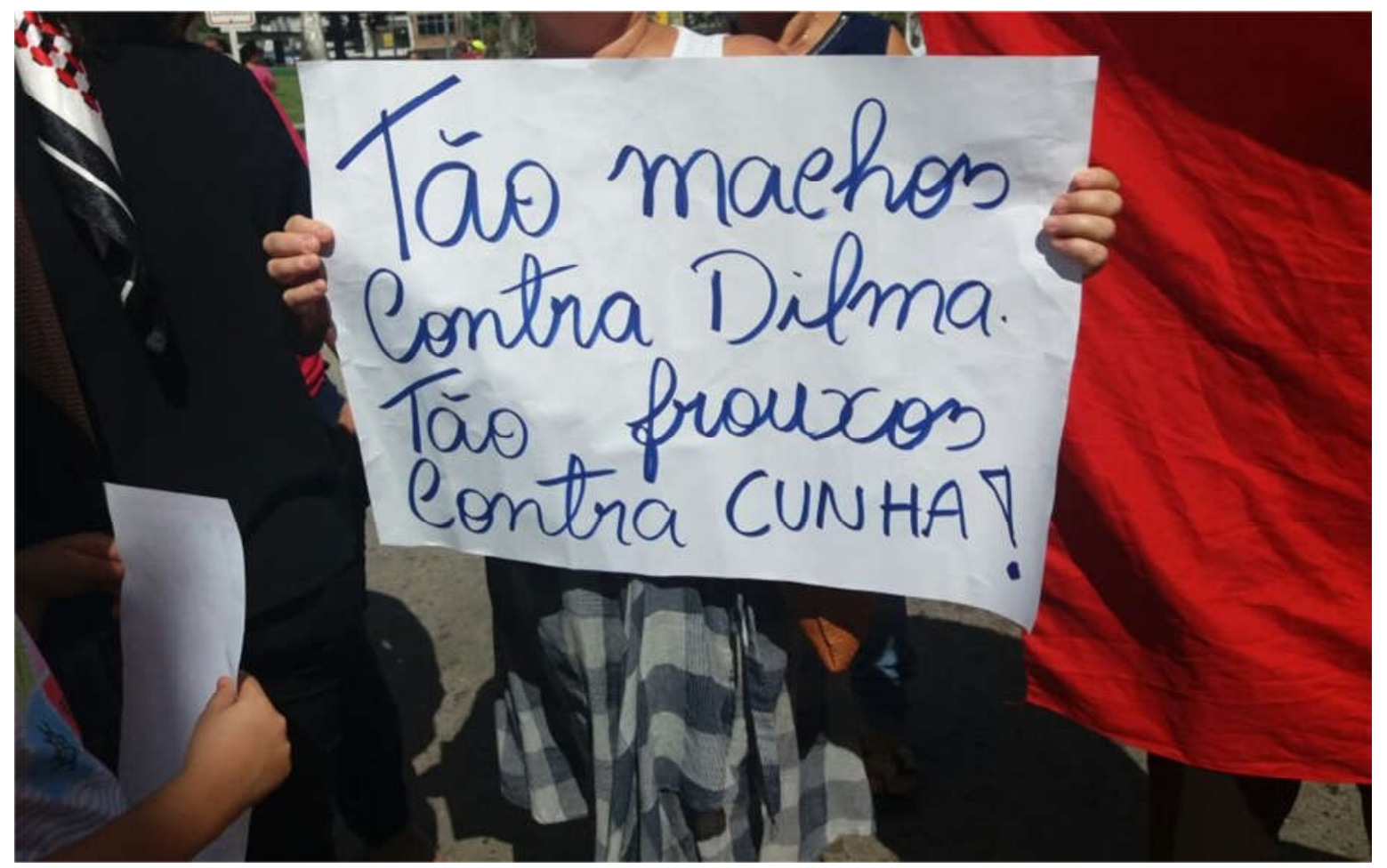

Imagem 5 


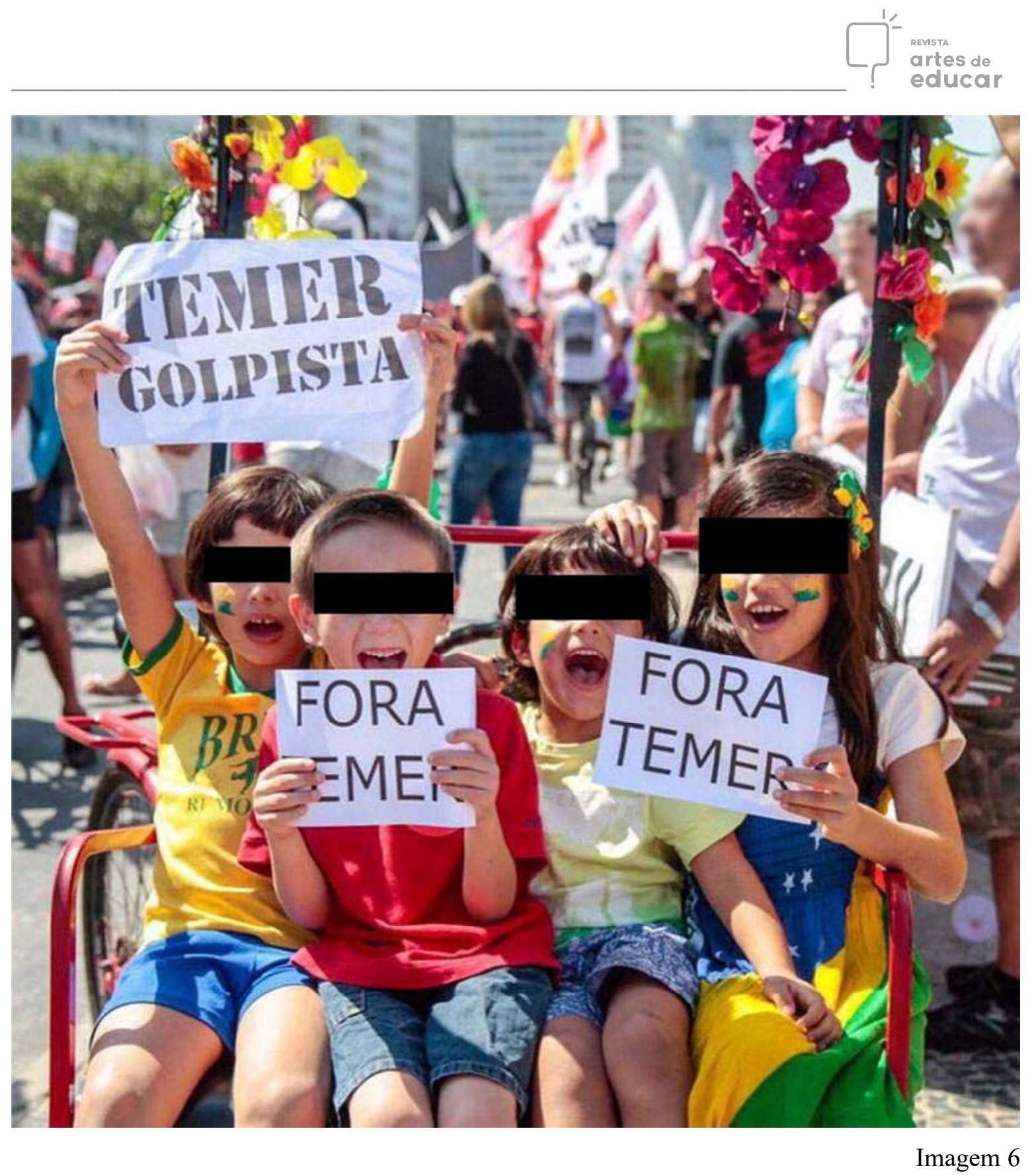




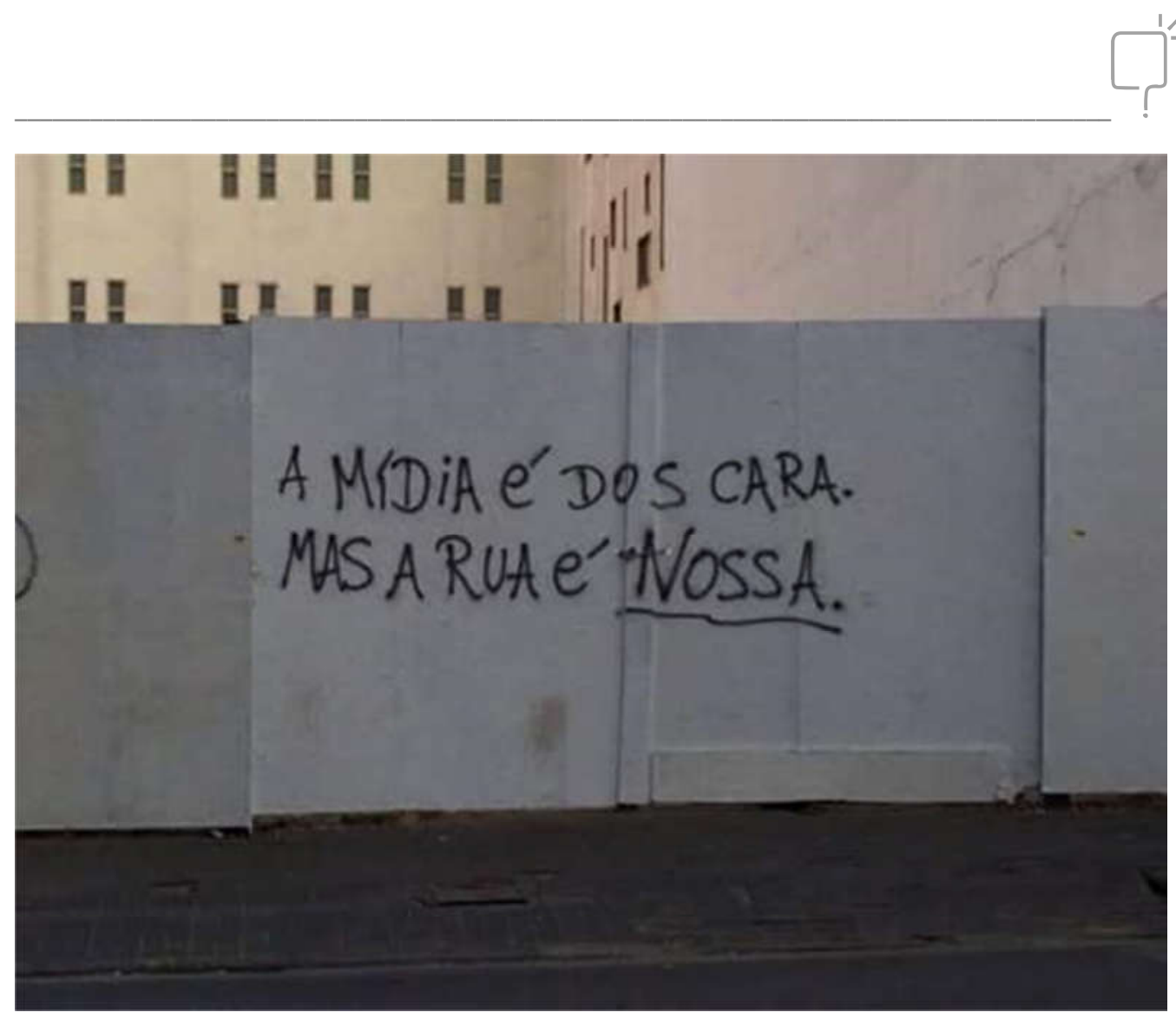

Imagem 7

Revista Interinstitucional Artes de Educar. Rio de Janeiro, V. 2 N. Especial - pag 235-252 (jun - out 2016): "Vozes da Educação" 


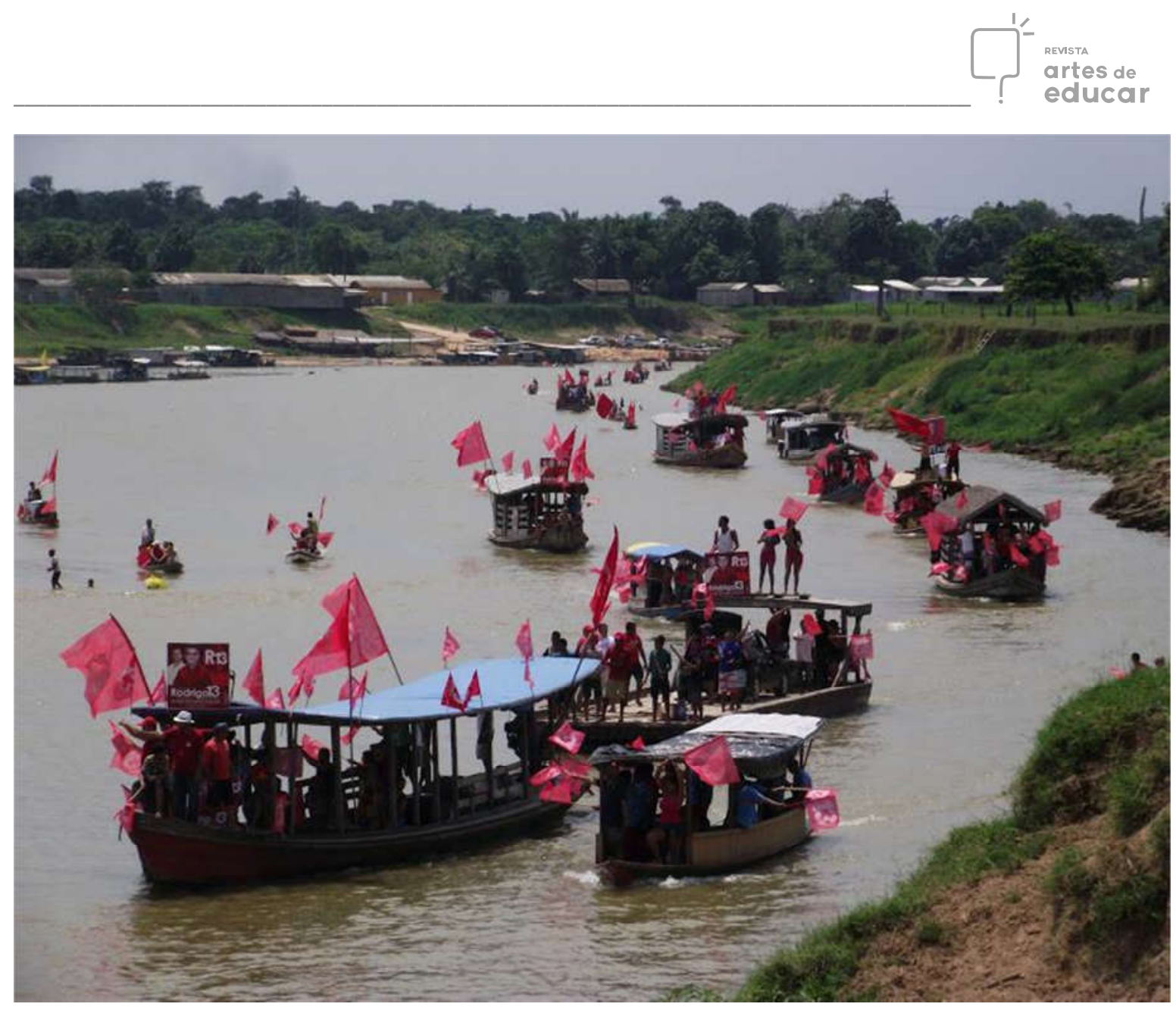

Imagem 8

Revista Interinstitucional Artes de Educar. Rio de Janeiro, V. 2 N. Especial - pag 235-252 (jun - out 2016): "Vozes da Educação" 


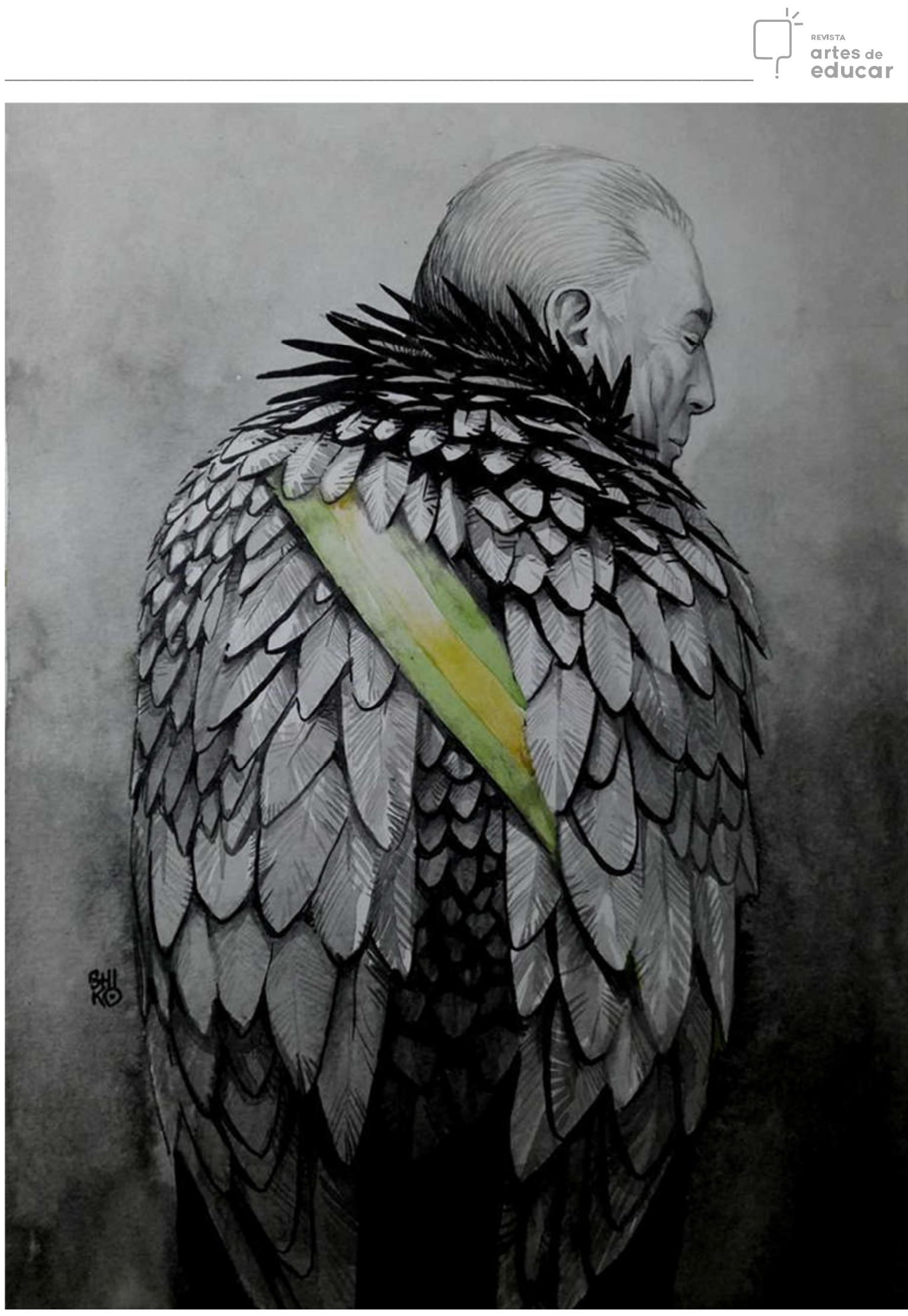

Imagem 9

Revista Interinstitucional Artes de Educar. Rio de Janeiro, V. 2 N. Especial - pag 235-252 (jun - out 2016): "Vozes da Educação" 
Da fotografia que fixa e coloca, em rede, algo que alguém escreveu em uma parede (Imagem 7); indo a uma foto de crianças sentadas em um carrinho usado na abertura das olimpíadas, com a frase na mão, feita pelo pai ou pela mãe de uma delas e postada no face (Imagem 6); passando pelo cartaz em cartolina que uma senhora segura denunciando os pesos diferentes de atuação frente a políticos (Imagem 5); indo a um desfile de barcos na Amazônia com inúmeras bandeiras que indicam em que lado da disputa estão (Imagem 8); passando por um desenho de artista que configura o presidente interino como um corvo (Imagem 9); chegando à criação de um 'personagem' - o barbudinho - que passou dias a procurar repórteres de rua da principal rede de televisão, segurando uma folha de papel A4, criticando esta mesma rede, em exemplo que passou a ser seguido por muitos (Imagem 10).

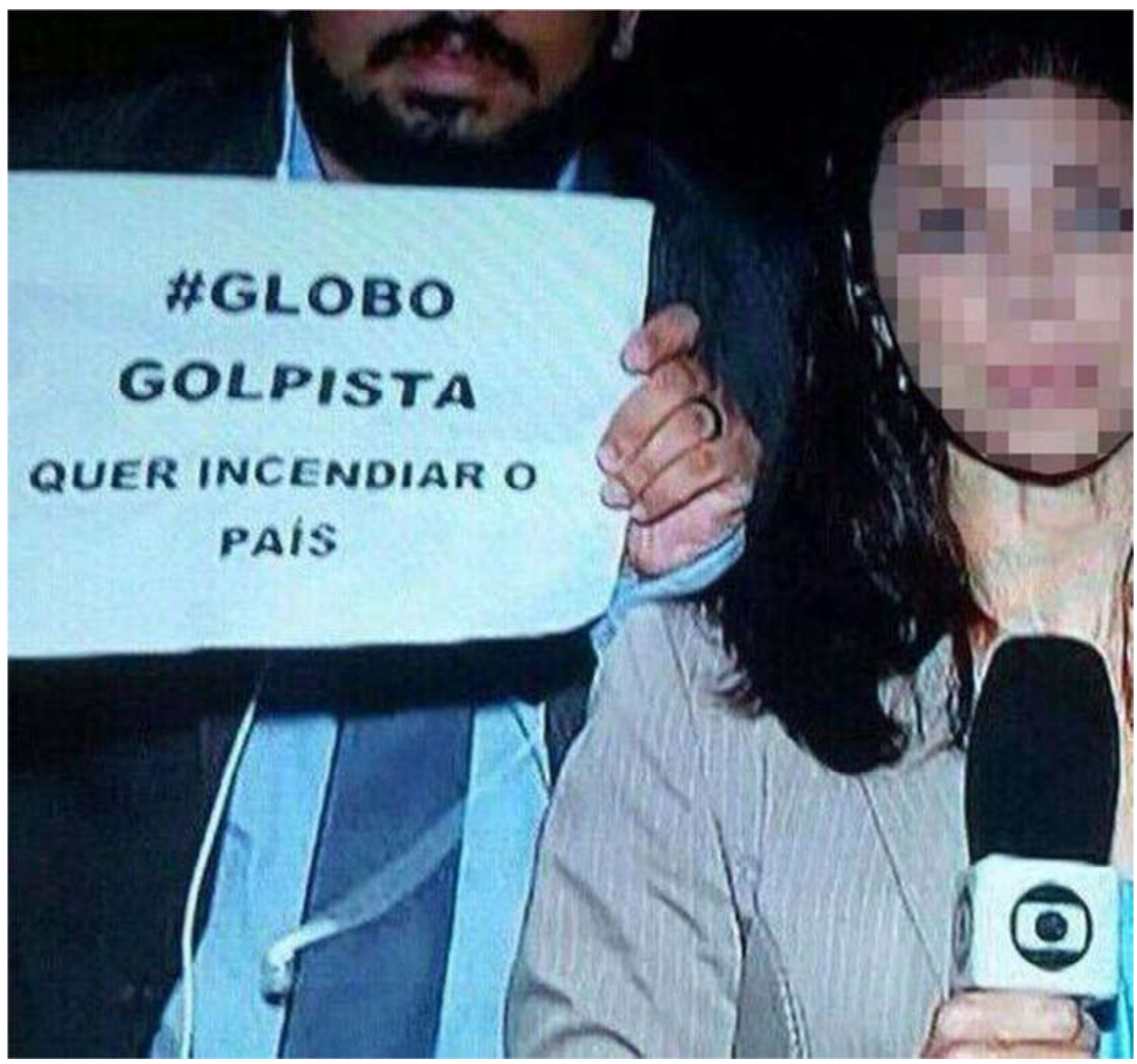

Imagem 10 
De um lado ou de outro, o ver vai sendo forjado a partir do crer, o que em nossa formação de pesquisadores com os cotidianos, em/com processos sociais e humanos exige parar para pensar muito a partir do que nos é apresentado, já que para Certeau (2012):

o 'simulacro' contemporâneo é, em suma, a localização derradeira do crer no ver, é o visto identificado com aquilo que se deve crer - uma vez que se abandonou a hipótese que esperava que as águas de um oceano invisível (o Real) viesse habitar as margens do visível e fazer delas os efeitos, os sinais decodificáveis ou os reflexos enganadores da sua presença (p.262).

No entanto, Certeau, nesta mesma obra dizia que o que interessava às pesquisas com os cotidianos era, também, outra coisa: que as pesquisas com os cotidianos são complexas, já que tratam de práticas que

volta e meia exacerbam e desencaminham as nossas lógicas. Encontra os lamentos do poeta e, como ele, combate o esquecimento: "E eu que me esquecia do acaso da circunstância, o bom tempo ou a tempestade, o sol ou o frio, o amanhecer ou o anoitecer, o gosto dos morangos ou do abandono, a mensagem, ouvida a meias, a manchete dos jornais, a voz ao telefone, a conversa mais anódina, o homem ou a mulher anônimo, tudo aquilo que fala, rumoreja, passa, aflora, vem ao nosso encontro"xiv CERTEAU, 2012: p. 43)

Reconhecendo que, no presente, a marginalidade não é mais de indivíduos, mas de grandes massas, Certeau começa por lembrar que são elas que pagam e compram o que é colocado para consumir, indicando que não são de modo algum homogêneas. Este imenso contingente de 'consumidores', no entanto, não o faz usando os manuais ou as bulas que acompanham os produtos colocados para consumo. Eles trabalham diretamente com os produtos - de ideologias a computadores; de filmes a músicas; de tudo a tudo - usando-os e com isto criando, permanentemente, novas tecnologias, novos conhecimentossignificações articulados em suas redes educativas e as necessidades que enfrentam no viver cotidiano.

Por isto, Certeau (2012) propõe que esses movimentos devam ser pesquisados em compreensão 'polemológica' ${ }^{\mathrm{xv}}$. Ele vai indicar, assim, que devemos entender estes movimentos como táticas que se dão em espaçostempos já apropriados, dizendo que

no espaço tecnocraticamente construído, escrito e funcionalizado onde circulam, as suas trajetórias formam frases imprevisíveis, 'trilhas' em parte ilegíveis. Embora sejam compostas com os vocabulários de línguas recebidas e continuem submetidas a sintaxes prescritas, elas desenham as 
astúcias de interesses outros e de desejos que não são nem determinados nem captados pelos sistemas onde se desenvolvem (p. 44-45).

É por isto que a criação pode se dar e vai aparecendo, aqui e ali, de modo complexo e bastante diferenciado, incorporando vez por outra o que se aprendeu em outras redes: os cartazes em cartolina e em folhas de A4 que abundaram nas imagens postadas na Internet, neste período, mostram, por exemplo, que os modos como aprendemosensinamos a expor ideias nas escolas, estão em nós como habitus (BOURDIEU, 1990; 1989). Esse material, por ser barato e existir com mais frequência nas escolas são muito usados por docentes e discentes.

E é com estas ideias que, entendo, poderemos compreender o momento presente, buscando ir além dele, com nossas dúvidas e descaminhos. Interrogar as imagens e os sons, com as tantas e tão diferentes narrativas que nos trazem, articulando, memórias, pontos de vistas, conhecimentossignificações, crenças expostas ou escondidas com o rabo de fora, buscando compreender "o ódio à democracia" (RANCIÈRE, 2014) ou sua defesa intransigente, parece-nos um bom caminho para buscarmos esta compreensão. Neste artigo, apenas iniciamos, muito timidamente este caminho.

\section{Referências}

ALVES, Nilda. Redes educativas, fluxos culturais e trabalho docente - o caso do cinema, suas imagens e sons - projeto de pesquisa (2012-2017). Rio de Janeiro: Laboratório Educação e Imagem/ProPEd/UERJ, 2011. (financiamento CNPq, FAPERJ, UERJ).

- Redes educativas 'dentrofora' das escolas, exemplificadas pela formação de professores. In: SANTOS, Lucíola, DALBEN, Ângela e LEAL, Júlio Diniz Leiva (Orgs.). Convergências e tensões no campo da formação e do trabalho docente: Currículo, Ensino de Educação Física, Ensino de Geografia, Ensino de História, Escola, Família e Comunidade. 66 ed. Belo Horizonte/MG: Autêntica, 2010: 49-66.

. A aula: redes de práticas - os processos cotidianos de ensinar e aprender. Rio de Janeiro: Faculdade de Educação/UERJ, 2000. (tese de titular)

ALVES, Nilda; CALDAS, Alessandra Nunes; ROSA, Rebeca Brandão. Filmes - imagens e sons- como memória afetiva de docente. Sorocaba/S.Paulo: Quaestio, v.18, n.1, maio/2016: $101-115$.

- Formação de professores com filmes: os clichês como formadores de docentes. S. Paulo: PUC-S. Paulo/Programa de Pós-graduação em Educação-Currículo. Revista e-Curriculum. Dossiê $\mathrm{ABdC}$ - "Formação Docente frente às políticas no cenário de centralização curricular", vol 13, n. 4, out-dez 2015: 775-793.

BOURDIEU, Pierre. Coisas ditas. S. Paulo: Brasiliense, 1990.

Revista Interinstitucional Artes de Educar. Rio de Janeiro, V. 2 N. Especial - pag 235-252 (jun - out 2016): "Vozes da Educação" 
. O poder simbólico. Lisboa: DIFEL, 1989.

CASTELLS, Manuel. Redes de indignação e esperança. Movimentos sociais na era da internet. Tradução: Carlos Alberto Medeiros. 1 ed. Rio de Janeiro: Zahar, 2013.

CERTEAU, Michel de. A invenção do cotidiano - 1. Artes de fazer. Petrópolis/RJ: Vozes, 2012.

DELEUZE, Gilles e GUATTARI, Félix. Os personagens conceituais. In DELEUZE, Gilles e GUATTARI, Félix. O que é filosofia? Rio de Janeiro: Ed. 34, 1992: 81-109.

OLIVEIRA, Francisco de. O Brasil em 2013: acabou a paz social (entrevista). Carta Maior. Em

http://www.cartamaior.com.br/?/Editoria/Movimentos-Sociais/O-Brasil-em-2013-acabou-a-pazsocial/2/29970 Visto em 21.06.2016.

OLIVEIRA, Inês Barbosa de. Currículos e pesquisas com os cotidianos: o caráter emancipatório dos currículos 'pensadospraticados' pelos 'praticantespensantes' dos cotidianos das escolas. In: Carlos Eduardo Ferraço e Janete Magalhães Carvalho (orgs.). Currículos, pesquisas, conhecimentos e produção de subjetividades. Petrópolis: DP et Alli, 2012: 47-70.

RANCIÈRE, Jacques. O ódio à democracia. S. Paulo: Boitempo, 2014.

SCHERER-WERREN, Ilse. Manifestações de rua no Brasil 2013: encontros e desencontros na política. Cadernos CRH. Salvador: vol. 27, n.71, maio-agosto/2014: 417- 429. In www.scielo.br/pdf/ccrh/v27n71/a12v27n71.pdf Visto em 21.06.2016

\footnotetext{
' Professora titular na UERJ e na UFF (aposentada em ambas); atualmente, pesquisadora sênior da UERJ, atuando no Programa de Pós-graduaçãoem Educação (ProPEd)/UERJ-Maracanã e no PPGEDU - Processos formativos e desigualdades sociais, da FFP/Uerj-S.Gonçalo. Pesquisadora $1 \mathrm{~A} / \mathrm{CNPq}$.

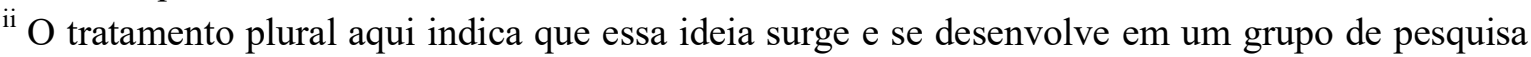
existente há anos: GrPesq Currículos, redes educativas e imagens, no CNPq.

${ }^{\text {iii }}$ São as seguintes as últimas pesquisas que desenvolvemos: Redes educativas, fluxos culturais e trabalho docente: o caso do cinema, suas imagens e sons (2012-2017); Memórias imagéticas da Universidade do Rio de Janeiro - algumas questões curriculares sobre o acervo fotográfico da UERJ (2009-2012); Artefatos tecnológicos relacionados à imagem e ao som na expressão de culturas de afro-brasileiros e seus 'usos' em processos curriculares de formação de professoras na Educação Superior - o caso do curso de Pedagogia da Uerj/campus Maracanã (2006-2009); O uso da tecnologia, de imagens e de sons por professoras de jovens e adultos e a tessitura de conhecimentos (valores) no cotidiano: a ética e a estética que nos fazem professoras (20032006); Memórias de professoras sobre televisão: o cotidiano escolar (2000-2003). Todas elas tiveram apoio do CNPq, da FAPERJ e da UERJ.
} 
iv Lembremos que as ideias contidas neste livro se referem à pesquisa realizada por Certeau entre 1974 e 1978.

${ }^{\vee}$ Depois de muitos anos utilizando a edição de 1997, decidi passar para a de 2012 que é aquela que os estudantes das turmas nas quais leciono conseguem adquirir. Na hora de nossas 'conversas' sobre o livro, as páginas diferentes nas duas edições estavam criando muita confusão!

vi Lembro que o subtítulo do livro é "1. Artes de fazer".

vii Este termo vem de Certeau (2012): ele trabalha com a ideia - central para seu modo de pensar - de que os 'praticantes', a que estamos chamando, coerentes com seu pensamento, de praticantespensantes, para além de 'consumirem' os produtos que lhe são apresentados a consumir - de ideologias a computadores - eles fazem 'uso' deles criando tecnologias e conhecimentossignificações outras, necessárias ao viver cotidiano.

viii Lembro que nas pesquisas com os cotidianos, os personagens conceituais são "aquelas figuras, argumentos ou artefatos que entram como o outro - aquele com que se 'conversa' e que permanece presente muito tempo para que possamos acumular as ideias necessárias ao desenvolvimento de conhecimentos e à compreensão de significações nas pesquisas que desenvolvemos. Esses personagens conceituais aí têm que estar, com as questões que nos ajudam a pensar, para que o pensamento se desenvolva, para que novos conhecimentos apareçam, para que lógicas se estabeleçam” (ALVES, 2011).

${ }^{\text {ix }}$ Observe-se que os únicos que se atrevem a 'olhar' o pobre deitado na rua são as crianças da imagem 1

${ }^{x}$ As palavras entre aspas e em itálico são de Certeau.

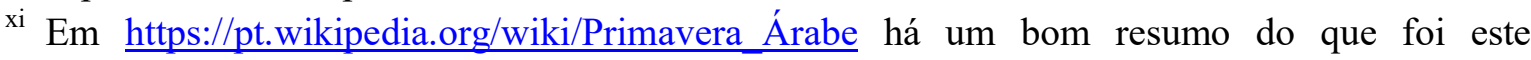
movimento

xii Ver o vídeo da repetição do que é dito pelo orador em: https://pt.wikipedia.org/wiki /Occupy Wall Street. Este modo de 'acontecer' foi visto com frequência nos movimentos de ocupação de escolas públicas pelos estudantes, no Brasil.

xiii Remeto a uma entrevista de Francisco de Oliveira, publicada em Carta Maior (OLIVEIRA, 2014). Indico ainda Scherer-Warren (2014).

xiv Nota 15 de Certeau (2012), referente a Introdução Geral: "Jaques Sojcher. La démarche poétique. Paris: UGE 10- 18, 1976, p145”. Está na p. 289 do livro referência.

${ }^{x v}$ Polemologia é o estudo científico das guerras e seus efeitos, formas, causas e funções enquanto fenómeno social. O termo foi proposto em 1946 pelo sociólogo e economista francês Gaston Bouthoul (1896-1980) no seu livro Cent millions de morts, tendo sido abraçado por múltiplas áreas das ciências militares, das ciências políticas e do estudos dasrelações internacionais. A aceitação da polemologia como um ramo de estudo no campo das ciências políticas pressupõe o abandono da aceitação da guerra como um fenómeno exclusivamente consciente e voluntário e de que os conflitos bélicos podem ser evitados utilizando mecanismos jurídicos de regulação da relação entre povos e Estados. https://pt.wikipedia.org/wiki/Polemologia, em 10.07.2016 